\title{
Selective Medium for Growth of Proteus
}

\author{
M. E. XILINAS, ${ }^{*}$ J. T. PAPAVASSILIOU, AND N. J. LEGAKIS \\ Department of Microbiology, Faculty of Medicine, National University of Athens, Athens, Greece
}

Received for publication 30 June 1975

\begin{abstract}
A medium containing heart infusion agar supplemented with bile salts, lithium chloride, sodium thiosulfate, and sodium citrate was developed for the selective growth of Proteus.
\end{abstract}

Proteus grow well on several media, but no selective medium exists for their primary isolation. Because we were interested in the isolation of clinical strains of Proteus to be used for antibiotic susceptibility studies, we have developed a selective medium for such isolation.

The medium has the following composition (grams/liter): heart infusion agar (Difco), 40.0; bile salts (Oxoid no. 3), 5.0; LiCl, 5.0; $\mathrm{Na}_{2} \mathrm{~S}_{2} \mathrm{O}_{3} \cdot 5 \mathrm{H}_{2} \mathrm{O}, 6.0 ; \mathrm{Na}_{3} \mathrm{C}_{6} \mathrm{H}_{5} \mathrm{O}_{7} \cdot 5.5 \mathrm{H}_{2} \mathrm{O}, 6.0$; water $1,000 \mathrm{ml}$. The $\mathrm{pH}$ of the medium was adjusted to 7.2; it was sterilized in the autoclave at $121 \mathrm{C}$ for $15 \mathrm{~min}$. The formulation of the medium was evaluated by testing a lot of antimicrobial substances, in different concentrations, using a rapid plating technique (3). The supplementation of the medium with bile salts, lithium chloride (1), sodium thiosulfate, and sodium citrate (2) at the concentrations stated above produced the selective growth of Proteus.

For qualitative evaluation of the medium, a total of 257 freshly isolated strains of Proteus from clinical material, including all the four species (Table 1), were examined. A total of 85 other bacterial cultures was also tested by a surface plating of a standard loopfull (diameter $3 \mathrm{~mm}$ ) from an overnight broth culture and by incubation at $37 \mathrm{C}$ for $24 \mathrm{~h}$. Three to ten cultures of the following were examined:Providencia stuartii, Escherichia coli, Klebsiella pneumoniae, Acinetobacter spp., Aeromonas spp., Citrobacter freundii, Bacillus subtilis, Bacillus cereus, Serratia marcescens, Salmonella typhimurium, Shigella flexneri, Streptococcus faecalis, Staphylococcus aureus, and Staphylococcus epidermidis. All but 12 strains of the Proteus tested grew prolifically (Table 1). The same has been observed with the five strains of $P$. stuartii examined (Providencia alcalifaciens were not tested). On the contrary, no growth could be observed among the other bacteria tested. Heavy inoculum of Pseudomonas aeruginosa gave a fairly sparse growth on the medium.

Colonies of Proteus spp. on our medium were moderate, large, thick, greyish-white, circular disks, dome-shaped and smooth. The opacity and size varied with different strains.

For the quantitative evaluation of the medium, parallel colony counts of Proteus were done, by surface plating, on this medium and on MacConkey agar (Oxoid no. 3). Such comparative studies were done in cultures from the exponential and stationary phase of growth. The results (Table 2) clearly demonstrate that the colony-forming ability of Proteus cultures from the exponential phase of growth is about the same on MacConkey agar and our medium; however, the size of colonies is somehow smaller. With cultures in the stationary phase, the viable counts on MacConkey agar exceeded those on our medium, whereas a significant diminution in the size of colonies was again noted. The results are in agreement with previous observations, supporting the view that the selectivity of the medium may be related to the size of the colonies of the microorganisms $(3,4)$, and to the existing difficulty of interpreting counts on selective media when the populations tested are not growing (3).

The usefulness of our medium for the direct isolation of Proteus from heavily contaminated inocula was partially assessed by mixing overnight cultures of Proteus mirabilis and $E$. coli with sterilized (Seitz filtered) feces and urine. Table 3 gives the numbers of microorganisms recorded after growth on MacConkey agar and our medium. It is evident that no difference

TABLE 1. Growth of Proteus strains on the selective medium

\begin{tabular}{lcc}
\hline \multirow{2}{*}{ No. of Proteus strains } & \multicolumn{2}{c}{ Positive cultures } \\
\cline { 2 - 3 } & No & $\%$ \\
\hline 168 P. mirabilis & 159 & 94.6 \\
32 P. rettgeri & 32 & 100 \\
31 P. vulgaris & 30 & 96.9 \\
26 P. morganii & 24 & 92.3 \\
\hline
\end{tabular}


TABLE 2. Recovery of Proteus strains in exponential and stationary phase of growth ${ }^{a}$

\begin{tabular}{|c|c|c|c|c|c|c|}
\hline \multirow[b]{2}{*}{ Strains } & \multicolumn{2}{|c|}{ Exponential phase $^{b}(\mathrm{CFU} / \mathrm{ml})$} & \multirow[b]{2}{*}{$\%^{c}$} & \multicolumn{2}{|c|}{ Stationary phase $^{d}(\mathrm{CFU} / \mathrm{ml})$} & \multirow{2}{*}{$\%^{c}$} \\
\hline & $\begin{array}{c}\text { MacConkey } \\
\text { agar }\end{array}$ & $\begin{array}{l}\text { Selective me- } \\
\text { dium }\end{array}$ & & $\begin{array}{l}\text { MacConkey } \\
\text { agar }\end{array}$ & $\begin{array}{l}\text { Selective me- } \\
\text { dium }\end{array}$ & \\
\hline \multicolumn{7}{|l|}{ P. mirabilis } \\
\hline $17 / 74^{e}$ & $1.2 \times 10^{8}$ & $0.9 \times 10^{8}$ & 75 & $1.5 \times 10^{9}$ & $7.8 \times 10^{8}$ & 52 \\
\hline $21 / 74$ & $9.5 \times 10^{7}$ & $1.1 \times 10^{8}$ & 110 & $8.4 \times 10^{8}$ & $7.2 \times 10^{8}$ & 85.7 \\
\hline $28 / 74$ & $1.5 \times 10^{8}$ & $1.9 \times 10^{8}$ & 126.6 & $7.9 \times 10^{8}$ & $6.2 \times 10^{8}$ & 107 \\
\hline $23 / 74$ & $3.0 \times 10^{8}$ & $3.1 \times 10^{8}$ & 103 & $1.8 \times 10^{9}$ & $9.4 \times 10^{8}$ & 52.2 \\
\hline $24 / 74$ & $2.8 \times 10^{8}$ & $2.4 \times 10^{8}$ & 86.1 & $5.9 \times 10^{8}$ & $2.6 \times 10^{8}$ & 45.2 \\
\hline \multicolumn{7}{|l|}{$P$. rettgeri } \\
\hline $1 / 74$ & $1.2 \times 10^{8}$ & $1.4 \times 10^{8}$ & 112 & $1.0 \times 10^{9}$ & $6.4 \times 10^{8}$ & 64 \\
\hline $132 / 74$ & $2.6 \times 10^{8}$ & $2.3 \times 10^{8}$ & 88.4 & $2.0 \times 10^{8}$ & $1.3 \times 10^{8}$ & 65 \\
\hline $134 / 74$ & $1.7 \times 10^{8}$ & $1.9 \times 10^{8}$ & 111.3 & $5.3 \times 10^{9}$ & $9.9 \times 10^{8}$ & 18.6 \\
\hline $209 / 74$ & $2.1 \times 10^{8}$ & $1.8 \times 10^{8}$ & 85.7 & $6.9 \times 10^{8}$ & $4.8 \times 10^{8}$ & 69.5 \\
\hline $217 / 74$ & $1.9 \times 10^{8}$ & $2.3 \times 10^{8}$ & 121 & $8.2 \times 10^{8}$ & $4.0 \times 10^{8}$ & 48.9 \\
\hline \multicolumn{7}{|l|}{ P. morganii } \\
\hline $18 / 74$ & $6.5 \times 10^{7}$ & $5.6 \times 10^{7}$ & 86 & $1.4 \times 10^{8}$ & $1.0 \times 10^{8}$ & 71.5 \\
\hline $31 / 74$ & $8.9 \times 10^{8}$ & $9.2 \times 10^{8}$ & 103 & $1.6 \times 10^{9}$ & $7.0 \times 10^{8}$ & 43.7 \\
\hline $41 / 74$ & $1.3 \times 10^{8}$ & $6.8 \times 10^{7}$ & 52.3 & $2.1 \times 10^{9}$ & $9.1 \times 10^{8}$ & 43.3 \\
\hline $47 / 74$ & $8.7 \times 10^{7}$ & $7.3 \times 10^{7}$ & 84 & $9.5 \times 10^{8}$ & $2.6 \times 10^{8}$ & 27.3 \\
\hline $48 / 74$ & $1.8 \times 10^{8}$ & $1.6 \times 10^{8}$ & 86.5 & $8.5 \times 10^{8}$ & $6.4 \times 10^{8}$ & 75.2 \\
\hline \multicolumn{7}{|l|}{ P. vulgaris } \\
\hline $16 / 74$ & $3.2 \times 10^{7}$ & $3.1 \times 10^{7}$ & 97.2 & $5.8 \times 10^{8}$ & $4.5 \times 10^{7}$ & 7.8 \\
\hline $19 / 74$ & $1.0 \times 10^{8}$ & $0.8 \times 10^{8}$ & 80 & $7.0 \times 10^{8}$ & $3.9 \times 10^{8}$ & 55.7 \\
\hline $26 / 74$ & $1.5 \times 10^{7}$ & $1.2 \times 10^{7}$ & 80 & $7.1 \times 10^{7}$ & $2.6 \times 10^{7}$ & 36.8 \\
\hline $55 / 74$ & $3.6 \times 10^{7}$ & $4.1 \times 10^{7}$ & 114.2 & $6.3 \times 10^{8}$ & $3.9 \times 10^{8}$ & 61.9 \\
\hline $66 / 74$ & $8.1 \times 10^{7}$ & $4.2 \times 10^{7}$ & 52.8 & $1.2 \times 10^{8}$ & $5.8 \times 10^{8}$ & 48.3 \\
\hline
\end{tabular}

a Incubation at $37 \mathrm{C}$ for $24 \mathrm{~h}$.

b 8 -h aged cultures. CFU, Colony-forming units.

c The number of colony-forming units on MacConkey agar is taken as $100 \%$.

d 48-h aged cultures.

${ }^{e}$ Laboratory numbers.

TABLE 3. Recovery of Proteus from artificial clinical material ${ }^{a}$

\begin{tabular}{|c|c|c|c|c|c|c|c|}
\hline \multirow{3}{*}{$\begin{array}{l}\text { Artificial } \\
\text { clinical mate- } \\
\text { rial }\end{array}$} & \multirow{2}{*}{\multicolumn{2}{|c|}{$\begin{array}{l}\text { No. added microorganisms/ml } \\
\text { (MacConkey agar) }\end{array}$}} & \multicolumn{4}{|c|}{ No. recovered microorganisms/ml } & \multirow{3}{*}{$\%$} \\
\hline & & & \multicolumn{2}{|c|}{ MacConkey agar } & \multicolumn{2}{|c|}{ Selective medium } & \\
\hline & E. coli & P. mirabilis & E. coli & P. mirabilis & E. coli & P. mirabilis & \\
\hline Feces & $1.5 \times 10^{7}$ & $1.2 \times 10^{7}$ & $1.4 \times 10^{7}$ & $1.3 \times 10^{7}$ & 0 & $1.15 \times 10^{7}$ & 96 \\
\hline Urine & $1.5 \times 10^{7}$ & $1.2 \times 10^{7}$ & $1.6 \times 10^{7}$ & $1.1 \times 10^{7}$ & 0 & $1.17 \times 10^{7}$ & 98 \\
\hline
\end{tabular}

a The artificial clinical material was prepared by adding $0.1 \mathrm{ml}$ from overnight cultures of $E$. coli and $P$. mirabilis in $1 \mathrm{ml}$ of sterilized (Seitz filtered) urine and feces saline solution.

exists in the recovery of Proteus from artificially contaminated feces and urine.

\section{LITERATURE CITED}

1. Baird-Parker, A. C. 1962. An improved diagnostic and selective medium for isolating coagulase positive staphylococci. J. Appl. Bacteriol. 25:12-19.
2. Haynes, M. 1942. The isolation of intestinal pathogens by selective media. J. Pathol. Bacteriol. 54:193-207.

3. Hoadley, A. W., and C. M. Cheng. 1974. The recovery of indicator bacteria on selective media. J. Appl. Bacteriol. 37:45-57.

4. Pattison, A. C., and F. A. Skinner. 1974. The effects of antimicrobial substances on Rhizobium spp. and their use in selective media. J. Appl. Bacteriol. 37:239-250. 